\section{Reinventing palliative care: hospice in hospital}

\author{
John Launer
}

The hospice movement is one of the great success stories of modern medicine. It largely owes its origin to a single pioneer, Dame Cicely Saunders. Trained successively as a nurse, then social worker, then physician, she became passionately devoted to the care of the dying. In 1967, she founded St Christopher's Hospice in south London, the first hospice in the world to combine pain and symptom management with clinical research, teaching and compassionate care. As a result of her energies and those of her followers, there are now over 200 hospices in the United Kingdom (UK), while the hospice movement has also spread to North and South America, Asia, Australia and New Zealand. Hospices have also encouraged a move towards providing terminal care in patients' own homes if they wish, generally delivered by hospice-trained staff working in the community alongside general practitioners (GPs) and primary care. Partly as a result of this impressive work, over 60 per cent of people in England say they would prefer to die at home, with around a further 30 per cent wishing to die in a hospice, and only a small minority expressing a wish to die in hospital. $^{1}$

In spite of all this success, there is still a large gap both in the UK and elsewhere between the kind of care people hope for at the end of life and what they receive. Only around a quarter of all deaths in England take place in hospices and at home. The majority still occur in hospital. Most hospitals now have a small, specialist team of palliative care doctors and nurses, who offer guidance to other staff. However, the services they provide are limited. In the UK, only around one in five hospitals have access to face-to-face services 7 days a week. 24-hour services on site are very uncommon. In theory, clinicians from other specialties should all be trained in good symptom control, but few hospitals follow the recommendation that this should be mandatory, while some offer no training at all. ${ }^{2} \mathrm{~A}$ number of recent reports have shown that the care of

Correspondence to Dr John Launer, Faculty Development, Health Education England, Stewart House, 32 Russell Square, London WC1B 5DN, UK; john.launer@nwl.hee.nhs.uk people in hospital with terminal conditions is often beset by poor levels of staffing and equipment, a failure to recognise impending death, over-treatment in a futile attempt to defer this, insufficient pain relief and hydration, a lack of proper decision-making about resuscitation, and inadequate communication with patients and relatives. ${ }^{3}$ There is also a great deal of variation in the quality of care provided to patients across the geographical areas, as well as between different conditions. ${ }^{4}$

\section{INTENSIVE NEEDS}

These facts are distressing, but in some ways not surprising. Although we might all hope to slip away from life peacefully, this is often not the case. The process of dying can be unpredictable and fluctuating. The unromantic reality is that people who are dying may groan in pain or thirst, call out in confusion, gasp with breathlessness, and cough or choke with secretions . As they weaken, they need frequent turning and lifting for comfort, and to perform natural functions. Anyone who has observed dying as a relative or carer will know that a patient's needs in the last days and hours of life may be intensive, complex, constantly changing from minute to minute, and causing distress to their relatives. Realistically, hospital wards often cannot meet this level of need, mainly because there are other patients who need attention and might recover as a result. Even in hospitals with the best training and highly motivated staff, it is hard to imagine a junior doctor calling a more senior one in the middle of the night for advice about a dying patient's need for hydration, or a matron allocating a full time nurse to a patient with a day or two of life expectancy, or a staff member stopping all other work for half an hour to attend to a distraught family.

One irony of this state of affairs is that patients who happen to die on intensive care units (ICU's) may receive better care than if they died elsewhere in the hospital. The level of nursing and medical care there is similar to that of a hospice, and staff will be used to continual monitoring of individual patients. For precisely those reasons, there is now a movement in the United States to establish ICUs that are especially dedicated to care at the end of life. ${ }^{56}$ While there are obvious objections to a convergence between critical and intensive care - including the wish to make dying less technological - the idea itself should prompt us to ask some difficult questions. For example, why do clinicians, institutions and societies prioritise the treatment of acute and potentially curable conditions over speedy and precise relief for the suffering of incurable patients? Indeed, why do we not offer antemortem care that is as good as the antenatal care we provide at its beginning? ${ }^{7}$

The answers to these questions are not simple. They include our reluctance to talk and think about death, as well as an understandable wish to preserve productive life, even if this comes at the expense of the frail. At the same time, hospitals are inescapably in the business of dying. Around a third of all patients in general hospitals are likely to be in their last year of life. ${ }^{8}$ Most people in the developed world will die in hospital, whether or not they expect to. This is for the simple reason that they will reach advanced old age, acquire multiple chronic conditions, need admission on a number of occasions for these, and sooner or later will deteriorate instead of recovering. This is an inevitable consequence of changing demography - and it may also be entirely acceptable. One study of bereaved families showed that nearly three quarters of people whose relatives died in hospital felt in retrospect that this was the best place to meet their needs, whatever preferences they had expressed in advance. ${ }^{9}$

\section{NEXT STAGE OF EVOLUTION}

There is now a widespread consensus that we need more investment in hospital palliative care teams, and these should be accessible 24 hours a day, 7 days a week. That is clearly right. At the same time, I wonder if we should consider a next stage of evolution in palliative care, by moving towards a fully resourced 'Hospice in Hospital' service. This could function in a similar way to palliative care teams in the community. Instead of simply having an advisory role, or a few dedicated beds, a service of this kind would offer mobile medical and nursing care day and night, anywhere in the hospital. It could take over direct care whenever a patient on the ward was in irreversible decline and needed more intensive support than routine ward staff could provide.

There would no doubt be concern from consultants and nurses from other 
specialities that direct provision of this kind would reduce continuity of care, and lessen their own experience of delivering palliative care. To set against this, a properly resourced hospice service for in-patients would make it possible to offer appropriate care to the dying at very short notice, even on the busiest medical and surgical wards. It would relieve ward staff from having to make unconscionable choices about where to allocate scarce human resources, and be a comfort to patients and families who fear dying in hospital and perceive this as a failure. Above all, 'Hospice in Hospital' would guarantee that everyone could meet with an equally comfortable death, regardless of where it occurred. Perhaps it is time to pilot such a service and evaluate it systematically. If most of us are not going to die where would chose, it might be more sensible for hospice care to be concen- trated in the places where we will actually need it.

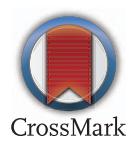

To cite Launer J. Postgrad Med J 2016;92:427-428.

Postgrad Med J 2016;92:427-428.

doi:10.1136/postgradmedj-2016-134276

\section{REFERENCES}

1 Gomes B, Calanzani N, Higginson IJ. Local preferences and place of death in regions within England 2010. London: Cicely Saunders International, 2011. https:/l www. palliativecarescotland.org.uk/content/publications/ Local-preferences -and-place-of-death-in-regionswithin-England-2010.pdf (accessed 31 May 2016).

2 Royal College of Physicians. National Care of the Dying Audit of Hospitals, England. London: Royal College of Physicians, 2014. https://www.rcplondon. ac.uk/projects/outputs/national-care-dying-audithospitals (accessed 31 May 2016).

3 Neuberger J. More care, less pathway: a review of the Liverpool Care Pathway. 2013 https://www.gov.uk/ government/uploads/system/uploads/attachment_data/ file/212450/Liverpool_Care_Pathway.pdf (accessed 31 May 2016).

4 British Medical Association. End of life care and medically assisted dying. London: British Medical Association, 2016. https://www.bma.org.uk/collectivevoice/policy-and-research/ethics/end-of-lifecare\#recommendations (accessed 31 May 2016).

5 Grumet J. Introducing the palliative care ICU, 2013. http:/ www.kevinmd.com/blog/2013/11/introducingpalliative-care-icu.html (accessed 31 May 2016).

6 Scott R. New model: merging palliative care and the ICU. http://www.dorlandhealth.com/dorland-healtharticles/new-model-merging-palliative-care-and-the-icu(accessed 31 May 2016).

7 Murray SA, Murray IR. End of life care still not living up to public and doctors' expectations. BMJ 2016;353:i2188.

8 Clark D, Armstrong A, Allan A, et al. Imminence of death among hospital inpatients: prevalent cohort study. Palliat Med 2014 28:474-79.

9 Office for National Statistics. National Survey of Bereaved People (VOICES) 2014. London: Office for National Statistics, 2015. http://www.ons.gov.uk/ peoplepopulationandcommunity/ healthandsocialcare/ healthcaresystem/bulletins/nationalsurveyofbereave dpeoplevoices/ 2015-07-09 (accessed 31 May 2016). 